\title{
Use of a New Mouthpiece in Placing a Nasobiliary Drainage Tube
}

In the setting of inadequate biliary drainage despite sphincterotomy, or debris left behind in the common bile duct, a nasobiliary drainage tube (NBDT) usually of 6$7 \mathrm{Fr}$ gauge, with a central guide wire, can be placed in the bile duct. It provides the possibility of follow-up cholangiographies, bacteriological studies of bile, and even application of gallstone solvents (1). To place an NBDT, the last step is to bring the tube out of the patient's mouth, and convert the orobiliary tube into a nasobiliary one by a nasogastric tube passed through the nose into the oropharynx, where it is usually grasped by the endoscopist's fingers. An uncooperative patient can add substantially to technical difficulties at this last stage, even though sufficient sedation with intravenous midazolam is usually applied. Accidental traumas to the endoscopist's fingers and to the tube 


\section{S4 Unusual Cases and Technical Notes}

itself may occur due to the uncontrollable behaviour of an uncooperative patient.

To protect the endoscopist and the NBDT, we designed a special lateral mouthpiece, the so-called lateral bite block. It is made of polymethylmethacrylate and was constructed in our dental laboratory. It has a simple handle to ease placement in the mouth and a special sulcus-like configuration between the acrylic wings preventing its dislodgment (Figures 1,2). After placement in the oral cavity, the patient bites the block with the lateral teeth and keeps it within the mouth. Because of its small diameter, there is enough space left in the mouth for manipulation by the endoscopist's fingers. We have successfully used it in intolerant patients, and have found that the frequency of traumatic events to the endoscopist and to the drainage catheters has been decreasing.

Y. Üstündag' ${ }^{\prime}$, C. Baysal', S. Boyacioglu', G. Gür' ${ }^{\prime}, M$. Gürsoy' ', P. Imirzaliog'lu ${ }^{2}$ S. Haydar ${ }^{2}$

' Dept. of Gastroenterology,

${ }^{2}$ Dept. of Medical Dentistry, Başkent University Hospital, Ankara, Turkey

\section{References}

1. Sherlock S. Diseases of the liver and biliary system, 8 th ed. London: Blackwell Scientific, 1989: 630-1.

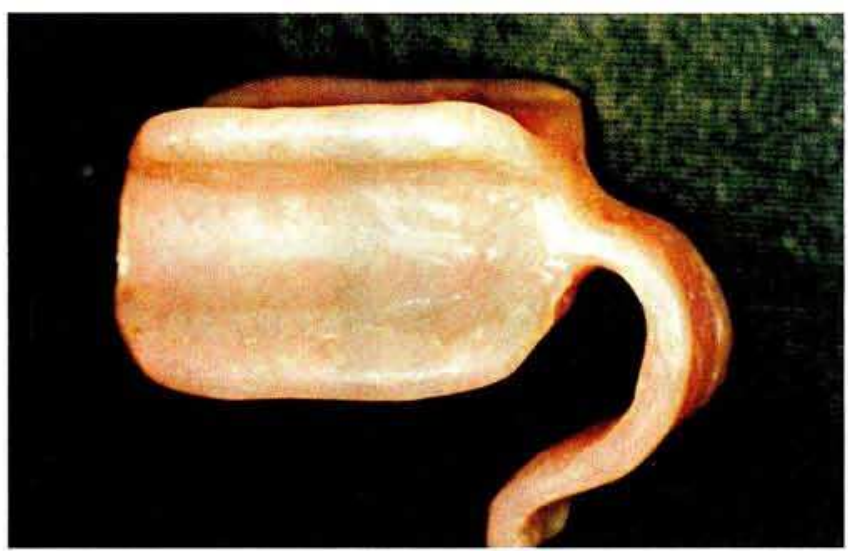

Figure 1: The lateral bite block with special sulcus-like configuration and a simple handle.

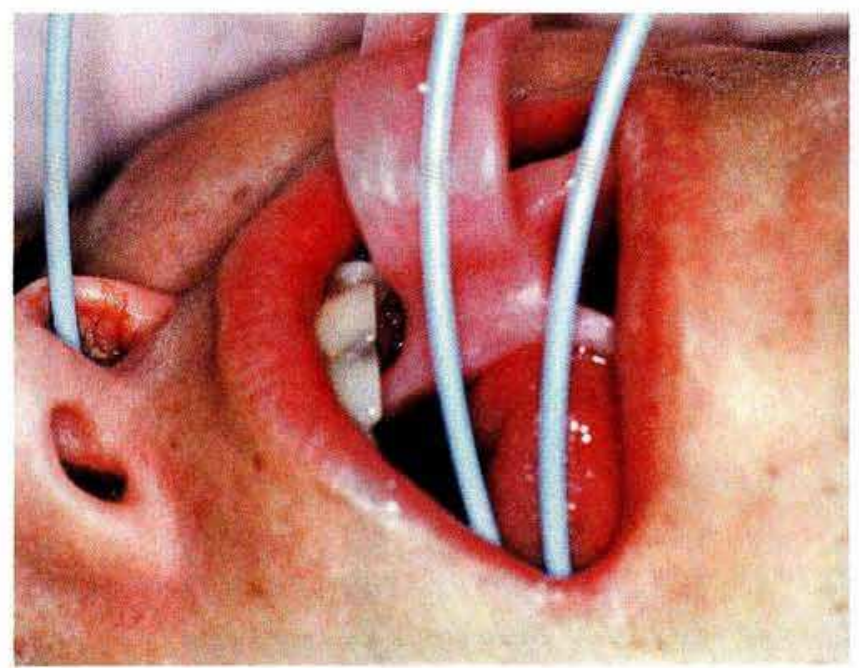

Figure 2: The lateral tion mouthpiece in posi-

Corresponding Author

Y. Üstündağ, M.D.

Dept. of Gastroenterology

Başkent University Hospital

Ankara, Turkey

Fax: $+90-312-2237333$ 